\title{
Participação Política Juvenil em Contextos de "Suspensão" D emocrática: a música rap na Guiné-Bissau
}

Miguel de Barros ${ }^{1}$

\section{Resumo}

A liberalização política nos inícios dos anos noventa nos países africanos de língua oficial portuguesa, favoreceu o surgimento de novos protagonistas no espaço público. Trata-se em particular de uma sociedade civil (organizada e não organizada) na qual a juventude e os meios de comunicação social tiveram (e têm) jogado um papel preponderante na ampliação dos espaços de contestação política e da liberdade de expressão. 0 presente artigo visa apresentar e analisar a emergência de um movimento contestatário na cidade de Bissau, resultado da articulação entre os músicos RAP e a utilização das rádios comunitárias, em particular a Rádio Jovem, o que contribuiu para dar visibilidade as denúncias e à reivindicação social e política por parte dos jovens num contexto onde os protestos são controlados e de baixa intensidade, transformando-os em atores ativos, incomodos e que formam a opinião pública.

Palavras-chaves: Guiné-Bissau, rap, jovens, rádio, participação

\footnotetext{
${ }^{1}$ Investigador associado ao Instituto Nacional de Estudos e Pesquisas da Guiné-Bissau - INEP, do Núcleo de Estudos Transdisciplinares de Comunicação e Consciência da Universidade Federal do Rio de Janeiro - NETCCON/URFJ (Brasil) e ainda membro do Conselho para o Desenvolvimento de Pesquisa em Ciências Sociais em África - CODESRIA (Senegal). Tem publicado em África, Europa e América do sul e desenvolvido pesquisas nos domínios da juventude, sociedade civil, media, feiras livres e música rap.
} 


\section{Political Participation of Y outh in Contexts of D emocratic "Suspension": rap music in Guinea Bissau}

Abstract

Political liberalization in the early nineties in the African countries of Portuguese official language, favored the emergence of new actors in public space. This is particularly a civil society (organized and unorganized) in which the youth and the media had (and have) played a role in the widening of spaces for political protest and freedom of expression. This article aims to present and analyze the emergence of protest movements in the city of Bissau, the result of coordination between rap musicians and the use of community radio stations, in particular the Rádio Jovem (Youth Radio), which contributed to give visibility to the allegations and social and policy claim for young people in a context where the protests are controlled and with low-intensity, transforming them into active players, troublesome and forming the public opinion.

Keywords: Guinea Bissau, rap, young, radio, participation

\section{Entre a instabilidade político-militar, o medo e a pobreza, o rap!}

A Guiné-Bissau, é um país da África ocidental com uma área de 36.125 quilómetros quadrados, é um dos países mais pobres do mundo, com PIB/habitantes situado na ordem de 254 dólares e um indicador de desenvolvimento humano de 0,396 em 2009, estando o país classificado em $173^{\circ}$ posição entre 182 países do ranking índice do desenvolvimento humano do PNUD. Quase dois terços $(65,7 \%)$ da população vivem com menos de 2 dólares por dia (Banco Mundial, 2009). A taxa de desemprego é de cerca de $30 \%$, sendo que os po- 
bres são na sua maioria jovens ( $80 \%$ entre 15 e 35 anos) (MEPIR, 2011: 38 e 97).

A história política recente da Guiné-Bissau foi atravessada por profundas transformações desde a proclamação unilateral da independência em 1973, depois de onze anos da luta armada, passando pela liberalização política nos inícios dos anos noventa e o conflito político-militar de 1998/99.

Desde este último evento, o país tem vivido em permanente instabilidade política e governativa que concorreu para a fragilização das instituições do Estado e da economia, acelerou os níveis da pobreza e insegurança e o país viu-se confrontado com o fenómeno de narcotráfico, (UNODC, 2007 e 2008; ICG, 2009 e 2012), resultando em golpes de estado baseado no jogo da presença dos militares na vida política num contexto de alianças feitas e desfeitas com políticos, dependendo das circunstâncias, impediu o país o benefício da estabilidade e alívio das tensões que tornam o desenvolvimento socioeconómico perspetivas difíceis, devido as constantes lutas pela captura e conservação do poder.

Em março de 2009, o Chefe de Estado Maior General das Forças Armadas e o Presidente da República foram barbaramente assassinados e em 2012 um golpe de Estado militar interrompeu o processo eleitoral para a presidência entre a primeira e segunda volta, destituindo o Presidente da república e o governo.

A incapacidade do Estado corresponder às expectativas de desenvolvimento coletivo e bem-estar pessoal da população nos quase quarenta anos de independência, a permanente instabilidade politica e consequente insegurança pessoal, socioprofissional e empresarial, contribuíram a para o surgimento de protagonismos de atores da sociedade civil, em todas as componentes sociais, mas de relativo alcance político. 
É dentro deste ambiente que o rap tem-se projetado como o instrumento adotado pelos jovens para contestação dos poderes (políticos e militares) e denúncia da situação sociopolítica visando a mobilização cívica dos jovens para um protagonismo de maior visibilidade, superando os níveis de uma certa passividades dos diferentes grupos de pressão, ganhando forma de expressão local e dessa forma, fomentando novas identidades locais, com base em autenticidades culturais, como sustenta Bennett (2000).

0 presente artigo, procura captar e analisar uma nova agência da apropriação do conceito da cidadania nos grupos juvenis, através de um movimento contestatário, principalmente na capital, Bissau, resultado de articulações entre os músicos rap e os produtores de programas das rádios, contribuindo para maior visibilidade e eficácia às reivindicações sociais e política por parte dos jovens, num contexto onde os protestos eram controlados e de baixa intensidade. Esta combinatória, projetou para a sociedade guineense a voz de uma categoria social cultural, política e socialmente excluída, transformando os rappers em atores incontornáveis da vida pública (Barros, 2012; Barros e Lima, no prelo).

\section{0 contributo das emissões radiofónicas na difusão da música rap guineense}

A adesão da Guiné-Bissau ao multipartidarismo em 1991, foi fruto de pressões externas e internas num contexto da falência do Estado suportado pelas políticas de ajustamento estrutural, e teve como consequências imediatas a afirmação e o reconhecimento de outros atores sociais coletivos (para além dos partidos políticos), enquanto agentes que participam nas decisões, lutam pela diminuição das desigualdades sociais, políticas e económicas. A ação de alguns sectores da Sociedade Civil (Igreja, Sindicatos, Organizações Não-Governamentais, Órgãos de Comunicação 
Social $^{2}$, Associações Profissionais e de Base Comunitária) contribuíram de forma decisiva quer para o ensaio à democracia, quer na promoção do desenvolvimento, no combate às desigualdades sociais e na melhoria das condições de vida das populações (Koudawo, 2000; Barros, no prelo).

Relativamente aos órgãos de comunicação social, estes evoluíram para um pluralismo maior, sobretudo no fim da primeira metade dos anos noventa. Os primeiros a quebrarem o monopólio do Estado foi a imprensa escrita no ano de 1992, seguida depois em 1995 das rádios. Neste universo, é a Rádio o meio de comunicação de excelência e de eleição ${ }^{3}$, por ter uma característica familiar (de proximidade) e abrangente, mais acessível (quer em termos de preços e utilização), reforçada pela cultura da oralidade em primazia na nossa sociedade e, também, devido ao condicionalismo da falta de infraestruturas, especialmente a que envolve a energia elétrica ${ }^{4}$.

É nesse contexto que emerge o primeiro programa radiofónico guineense dedicado ao rap. Em Julho de 1996 foi emitido, através das antenas da rádio privada "Pindjiguiti", o programa "rap pa raperus ${ }^{5 "}$, com uma hora semanal, visando a promoção deste estilo no panorama da música nacional, a expressão dos jovens

\footnotetext{
${ }^{2}$ A maior vitalidade foi registada no campo das rádios de cariz comunitário e local, dando maior visibilidade aos problemas que afetam o quotidiano das populações, podendo ser a própria população, em particular os jovens, os protagonistas da ação. Neste momento, a Guiné-Bissau conta com uma rede nacional de rádios comunitárias com mais de três dezenas de rádios inscritas, que cobrem todo o país.

${ }^{3}$ A alfabetização é muito baixa no país. Em 2010, a taxa de alfabetização era de 62\%, sendo que para as mulheres de 15 a 24 anos foi de 39,9\%, a nível nacional, 50,45\% em Bissau, e apenas 9,7\% nas zonas rurais, o que ilustra a magnitude do desafio para garantir a qualificação dos recursos humanos na Guiné-Bissau. Cf. DENARP II, 2011.
}

${ }^{4}$ A Guiné-Bissau não tem conseguido criar condições para o abastecimento do país em termos da energia elétrica. Só 5,7 \% da população tem acesso e ainda de forma irregular. Esta proporção é de 12 \% na capital, Bissau. Cf. DENARP I, 2005.

${ }^{5}$ Fazedores e amantes do rap. 
rappers e dos que se identificavam com este novo estilo e com as mensagens veiculadas.

Apresentado por dois jovens que faziam sistematicamente recurso a uma inovadora linguagem calão ${ }^{6}$, os primeiros grupos nacionais a merecerem destaque neste espaço foram os Thunder Body 5, Isca № 0, I.C.G.D., Black Doggers, ITC Grusman, Naka B. (um dos que faziam parte do agrupamento Dance Biss), Fafa D. Masta Kolly e TCC 4. Estes aproveitavam as entrevistas no programa para fazer as suas gravações com mímica, batendo palmas e batucando na mesa. Tal fato fez com que o mercado de venda de beats abrisse as suas portas no país, facto que teve como corolário o desencorajamento do playback como meio de produção da música rap, em particular da música juvenil na capital.

Na entrevista a um dos apresentadores do programa "rap pa raperus", ele afirmou o seguinte:

Tornamos os jovens mais criativos e produtivos. Contribuímos para retirar a carga negativa que já estava a se instalar sobre os rappers, pois no início eram conotados com bandidos, preguiçosos e que desprestigiavam a cultura nacional. (Gomes, Cícero Spencer. [Bissau: Guiné-Bissau]: 14 janeiro de 2012. Entrevista concedida a Miguel de Barros)

O jornalista e ex director de antena da rádio Pindjiguiti exalta que:

0 programa (rap pa raperus) através da rubrica «concurso de rima temáticas» permitiu dar visibilidade às denúncias e à reivindicação social por parte dos jovens, num país onde os protestos são murmúrios. (Conté, Muniro. [Bissau: Gui-

\footnotetext{
${ }^{6}$ Foi através destes que o calão recriado no rap teve uma difusão mais sistematizada e os termos como Codiga - ntindi [compreensão] / Spiga - purblema [problema] / Kiki djubi [ver/olhar] / Mantison di hablason - conbersa [conversa] / Si matola - parvo [tolo] / Cainga [polícia] / Bófia [polícia] / Baza [ir embora] / Forgeta-diskisi [esquece] / Nepia [nada] / N'bitan - patin [oferece-me] / Taco-dinheru [dinheiro] / Kaula [compra] / garé [cigarro] / Cubico [quarto]..., acabaram por entrar no quotidiano do crioulo urbano e juvenil, articulando as importações dos termos em inglês, português (através das músicas) espanhol (devido ao retorno de contingente de emigrantes) e crioulo antigo.
} 
né-Bissau]: 19 novembro de 2011. Entrevista concedida a Miguel de Barros)

O programa radiofónico "rap pa raperus" conseguiu manter-se no ar, ininterruptamente, durante dois anos ${ }^{7}$, sem evitar algumas ameaças aos promotores de serem detratores de uma certa cultura nacional, como também por parte de alguns jovens que entendiam que o facto de os apresentadores usarem o calão, poderia descodificar as mensagens e deixá-los ficar mais vulneráveis. Não obstante a isso, o programa assumiu uma postura de potenciação do estilo musical, como os apresentadores do programa estiveram a liderar um processo de criação, em 2000, de uma associação de rappers (sem personalidade jurídica), que neste momento conta com um programa próprio na rádio pública, a Guiné-Rap.

Com o conflito político-militar de 1998-99, os órgãos de comunicação social sofreram impactos catastróficos: as instalações da rádio Pindjiguiti foram completamente saqueadas, a rádio Mavegro perdeu parte do seu equipamento e a rádio Bombolom foi ocupada logo no primeiro dia do deflagrar do conflito, transformando-se na rádio Voz da Junta Militar. Quanto às rádios comunitárias, elas foram simplesmente silenciadas, visto que a maioria delas era gerida por Organizações Não-Governamentais. No período pós-guerra civil, muitos jornalistas foram perseguidos, presos e espancados, jornais foram ameaçados de terem os seus alvarás cancelados, e houve invasão de espaços de algumas rádios. 0 princípio da liberdade de imprensa, outrora em franca projeção, foi seriamente enfraquecido por falta de um ambiente político institucional, económico e social favorável ao seu exercício efetivo (Koudawo, 2000: 98-99 e 109).

É nesse encadeamento que, em 2005, foi criada a Rádio Comunitária Jovem, uma iniciativa da Rede Nacional das Associações

${ }^{7}$ O programa ficou suspenso pela primeira vez com o despoletar do conflito político-militar de 1998-99, tendo sido retomado em 2000, já num novo formato e só com um apresentador. 
Juvenis (RENAJ), que é uma estrutura independente do governo, dando corpo a uma dinâmica participativa juvenil marcada pelo entusiasmo, consciencialização perante os problemas e necessidades sociais, vontade de compromisso pela melhoria e transformação da realidade, enquanto bases poderosas que assistiam esses jovens e associações (Barros, 2010: 10-11). Deste modo, o propósito da rádio foi dar o eco às vozes dos jovens e estimular a criatividade juvenil, bem como a promoção da mobilização dos jovens através do associativismo.

Da grelha de programação da Rádio Jovem, destaca-se o programa "Ondas Culturais". Emitindo por dez horas durante a semana, em crioulo. 0 programa trouxe novos talentos e valores da música jovem feita pelos guineenses, apresentou os seus currículos, deu-lhes espaços para entrevistas em direto, abriu linha telefónica para que estes dialoguem com os ouvintes, criou um top semanal/mensal/anual das músicas mais rodadas e ainda mobilizou-se para premiar os melhores músicos jovens e as músicas da nova geração guineense. Tudo isso aconteceu numa perspetiva voluntária, feito por jovens animadores que nunca antes tinham passado pelas escolas de jornalismo ou comunicação social.

Foi dessa forma que as músicas interventivas do FMBJ, Masta Tito, Torres Gemeos, Real Power, Cientistas Realistas, Raínha Luísa, Rock Salim, Bunca MC, Baloberos, Dama Cotche (Os Bravos), Raça Preto, Fil Cap, Best Friends, Daw Tchaw.... começaram a ganhar mais notoriedade e protagonismo. Num momento em que a intervenção militar na vida política e no espaço público era (e é) uma constante, perseguidos e algumas vezes espancados por estes, os rappers assumiram o papel de críticos e contestatários, repudiando essa postura. E as rádios, ao desenvolverem este papel de posicionarem-se na interface entre os acontecimentos e o público ouvinte, transmitiram um testemunho bastante particular, que os partidos políticos e o discurso público não ousavam e nem conseguiam criar condições para o ter e fazer. 
Um outro papel exercido pelo programa "Ondas Culturais" e pelo programa "Campeonato de RAP", emitido todas as sextas-feiras, à noite, na rádio Pindjiguiti, foi a maior divulgação e promoção dos rappers guineenses na diáspora. São os casos dos países recetores de contingentes de estudantes guineenses, onde podem ser identificados nomes como N’pans, Okarki Butt e MC Bunka (Rússia), Djokas, MC Mário, Issuf/Wane (Portugal), Lem (Brasil) e Fafa D (Senegal).

No programa "Ondas Culturais", são promovidos concursos de freestyle todas as sextas-feiras, sendo que as vezes, esses concursos são realizadas na varanda da própria estação, servindo de palco para diferentes rappers estarem em contacto direto com os ouvintes, e por outro lado, permitindo ainda os ouvintes ligarem para votar nas músicas que se estreiam durante a semana, para eleger o top mensal, por outro. No "Campeonato de Rap", para além do discurso enquanto elemento encantatório da recriação da língua crioula, através da rubrica "estilo livre" e do novo repertório, as apresentações das biografias destes músicos interventores associados ao favorecimento de maior acesso às produções e divulgações de videoclipes disponível online, contribuiu para encorajar a produção nacional e ainda reforçou a legitimidade e a necessidade das mensagens, contribuindo para com que a opinião pública e política começassem a absorver (consumindo) e (re)produzir um discurso público com maior nível de (re)conhecimento dos problemas que o país enfrenta, como a instabilidade política, a questão do narcotráfico, uma eventual corrupção no aparelho administrativo público, a tendência à impunidade, o funcionamento precário dos sistema de ensino e saúde, desemprego, etc.

Ao analisar a forma como os apresentadores destes programas assumem a sua condição nas rádios, denota-se aqui o alargamento do papel do "tcholonadur", ou seja, "o mensageiro", que

\footnotetext{
8 "Figura necessária, mesmo indispensável, com significados diversos, tanto nas culturas com base nas chamadas religiões naturais, como nas coletividades muçulmanas. Quando há algo a tratar entre dois contraentes, muitas vezes falantes de diferentes línguas, se-
} 
ao contrário da literatura, as rádios traduziram a necessidade e a emergência de vozes atuantes dos jovens que se faziam ouvir por todos os cantos.

\section{O s palcos da contestação e a consagração da música rap guineense}

Na transição das rádios para os palcos o rap guineense foi e é marcado pelas mudanças importantes no campo das identidades adotando os nomes e símbolos nacionais, da estética musical articulando ritmos e instrumentos tradicionais (tambor ${ }^{9}$, kora $^{10}$, balafon ${ }^{11}$, tina ${ }^{12}$, nhanheru ${ }^{13}$, sikó ${ }^{\square}$ e bombolom ${ }^{14}$ ), fazendo

gundo os costumes locais, não é possível que os dois dialoguem diretamente, tornando-se necessária a presença de um terceiro, tradutor, mediador ou intermediário, que então passa para cada um o que o outro diz ou responde. A posição dos oponentes, muitas vezes sentados de costas virados um para o outro, simboliza a distância, o antagonismo que o tcholonadur tenta superar" (AUGEL, 2003: 188).

${ }^{9}$ Também chamado de djembê, é um tipo de tambor originário da África ocidental, um instrumento importante de percussão (membranofone) que possui o corpo em forma de cálice e a pele tensionada na parte mais larga, que pode variar de 30 a 40 centímetros de diâmetro. 0 som do tambor é obtido por percursão directa com as palmas das mãos.

${ }^{10}$ Harpa-alaúde de 21 cordas, é um instrumento sagrado e místico amplamente utilizado pelos “Mandingas", um dos maiores grupos étnicos da África ocidental originário.

${ }^{11}$ Instrumento originário da costa ocidental de África e precursor do xilofone, possui um reduzido número de teclas e utiliza uma solução de cabaças para os ressonadores. 0 seu formato é retangular com amarrações em couro e cordas, tocado com duas baquetas.

${ }^{12}$ Instrumento musical originário da Guiné-Bissau, mais precisamente um idiofone repercutido, conhecido como tambor da água utilizado pelos grupos de mandjuandade. É constituído por um recipiente cilíndrico, quase que cheio de água, onde se encontra a boiar uma cabaça oca e é tocado batendo com a palma da mão e punho na cabaça, produzindo um som grave e de grande intensidade.

${ }^{13}$ Originário da África Ocidental, é uma espécie de violino de 3 cordas, utilizados sobretudo pela etnia "fula", constituído, na parte cava, de oco de cabaça

${ }^{14}$ Originário da Guiné-Bissau, bombolom é um instrumento musical utilizado por alguns grupos étnicos animistas e serve fundamentalmente para transmitir mensagens e está presente em rituais de grande importância, como, cerimónias fúnebres. 
sample de músicas nacionais clássicas de intervenção, mensagem watcha-watcha (terra-terra) - anti-metafórica e explícita, e da personagem dos próprios rappers - membros das associações juvenis, estudantes universitários, profissionais, e as rádios difundiram toda essa mudança.

Um desses exemplos foi a canção "Ke ki mininu na tchora", ou seja, por que chora o menino, de José Carlos Shwarz, grande expoente da música guineense, combatente da liberdade, da independência e o pioneiro da música moderna. Este artista musicalizou o poema em forma de registo verbal que contava os horrores da guerra colonial, como podemos observar no trecho "Ke ki mininu na tchora/I dur na si kurpu/ ke ki mininu na tchora/I sangi ki kansa odja" ["Por que chora o menino?/Tem muita dor/Por que chora o menino?/Viu demasiado sangue" (Schwarz, ke ki mininu na tchora, registo sonoro, Bissau, 1977).

Essa música emblemática no cenário cultural guineense, foi atualizada pelos “Torres Gémeos”, para denunciar a situação política e governativa no contexto contemporâneo.

Ke ku guineensis na tchora?/e na tchora no governantis pa maldadi ku ten na tera/Ke ku guineensis na tchora?/e na tchora no militaris ku ka disanu vivi na paz [Por que choram os guineenses?/Por causa dos governantes, da maldade que existe na nossa terra/Por que choram os guineenses?/Por causa dos militares que não nos deixam viver em paz]. (Torres Gémeos, culpadus, registo sonoro, Bissau, 2008)

Sendo o rap de intervenção politicamente engajado e militantemente inquieto como elucidam Contador e Ferreira (1997), este foi o momento crítico onde, em rutura com a experiência ordinária do tempo como simples redução do passado, tudo (mesmo que aparentemente) tornou-se possível quando os artistas resgataram José Carlos Schwarz, que nos primeiros momentos da pós-independência anunciara: "Gos ku ora di canta tchiga/Ninguin ka ten garganti [agora que chegou a hora de cantar/ ninguém tem a voz]. (Shwarz, Ora di canta tchiga, registo sonoro, Bissau, 1977). 
É com este sentimento de continuar e atualizar o legado que estes rappers, mesmo conscientes dos riscos que corriam, deram a voz ao manifesto, como é aqui narrado pelos FBMJ na introdução da interpretação do "Kaminhu Sukuru" [Caminho Escuro]:

Es musika antis ki na kunsa/no panti ba dja Hospital Nasional Simon Mendes/nunde ku no lantanda no sartidon di obitu/i na sobra so data ku hora pa kin ku na mata pa i sina! [Antes de começarmos esta música/passámos pelo Hospital Nacional Simão Mendes/levantar a nossa certidão de óbito/ Só falta a data e a hora para o matador assinar]. (FBMJ, $\mathrm{ca}$ minhu sukuru, registo sonoro, Bissau, 2008)

Esta assunção interventiva ganhou maior combatividade na medida que os rappers apresentaram-se na condição de desencadeadores da luta contra o sistema vigente e a cultura do medo - "Pau-pau a Luky-Luke/nha bala ka ta libra nin un marchal [...] federal [...] Ku fadin ba jeneral [Pau-pau à Lucky-Luke/As minhas balas não poupam nem um marechal [...] Federal [...] Quanto mais generais]. (Naka B., Coli-coli sensa, registo sonoro, Dakar, 1999). Ou "Si RAP i pistola no na sedu si bala!/Hip-hop GuinéBissau, FBMJ toleransia zero" ["Se o rap é pistola, nós seremos balas!/Hip-hop Guiné-Bissau, FBMJ tolerância zero"] (FBMJ, caminhu sukuru, registo sonoro, Bissau, 2008).

Contudo, os "Torres Gémeos" fazem descortinar as causas da ausência da crítica e do protesto na sociedade guineense na atualidade, como no excerto abaixo.

[...] boka di pubis na tirmi ku bontadi di papia/Ma medu forka se boka ma abos tudu bo sibi pabia/Ma pabia?/Djintis medi denunsia pabia di janta ku sia/se konta, ah [...] kamaradas pudi ka fia/é o é ka fia, é pudi tchomadu pa bofia/pa turturadu sekretamenti suma di kustumi/pa kila kulpadu na nô metadi nunka no ka na tchoma si nomi/kusta no sedu basora koruptu, ma no ka ta muri di fomi [ [...] A boca do povo treme de vontade de falar/Mas o medo amordaça-a, todos sabem porquê/Porquê?/As pessoas têm medo de denunciar por causa de almoço e jantar/Se contarem, ah [...] Os camaradas 
podem não acreditar/E acreditando ou não, podem ser chamados à bófia/Para serem torturados secretamente como de costume/Por isso entre nós nunca é denunciado o culpado/Podemos ser lambe-botas, mas não morremos à fome]. (Torres Gémeos, culpadus, registo sonoro, Bissau, 2008)

[...] bardadi na tchikinin, n' misti papia ma seguransa keia/ bófias ka pupa ninguin ku ta konta ke na aldeia/i fasil sedu koruptu pabia fin di mis ka ta tchiga/pursoris ta bindi nota pabia fin di mis ka ta tchiga [...] médikus ta bindi mesinhu pabia fin di mis ka ta tchiga [...] pa paga skola di mininu, renda ku djanta ku sia/deputadus na risibi bilions, na disidi sakalata/ministrus na risibi bilions, na fasi patarata/bolsas na ministérius na bandeja ki ta kulkadu/si bu pape ka tene setesentus bu ka ta selesionadu/enkuantu patetas di karteras na perta stangu/formadu sin tarbadju purpara stangu pa kuntangu/enkuanto patetas di kartera na perta stomagu ku frangu/bu ten ku sedu PRS, PUSD o PAIGC/pa bu tene un bon tarbadju, kasa o GMC/si nau bu na bedjusi bu kabesa na kume kaseke"[ [...] A verdade faz-me cócegas, quero falar mas não há segurança/Os bófias não poupam ninguém que falar na aldeia/Tornam-no corrupto porque o salário não chega/Os professores vendem as notas porque o salário não chega [...] Os médicos vendem os remédios porque o salário não chega [...]para pagar a escola das crianças, o aluguer e a comida/ Os deputados recebem biliões e decidem asneiras/Os ministros recebem biliões e fazem besteiras/Nos ministérios as bolsas são postas à venda/Se o teu pai não tem setecentos não és seleccionado/Enquanto os patetas nas carteiras apertam o cinto/E os formados sem emprego se preparam para comer arroz limpo/Enquanto os patetas nas carteiras apertam o cinto com frango/Tens que ser PRS, PUSD ou PAIGC/Para teres um bom emprego, casa o GMC/Se não, vais envelhecer a comer peixe seco]. (Torres Gémeos, culpa$d u s$, registo sonoro, Bissau, 2008)

Já no palco e exposto, uma das estratégias utilizadas pelos rappers, foi fazer featuring e actuações ao vivo com músicos nacionais consagrados, podendo passar as mensagens sem que os concertos sejam interrompidos e/ou eles torturados. Não é consenso, mas numa perceção muito particular, entendemos que esta imaginação não deverá ser interpretada apenas do ponto 
de vista estrito da segurança, pois como sustenta Sclavi (2000), as emoções são instrumentos de conhecimento fundamentais, se apenas sabemos compreender sua linguagem, o código delas é relacional e analógico.

É neste contexto de repressão que a nova expressão musical e interventiva urbana conquista maior performance e se consolida entre a ação musical e a resposta do público, pela atualidade das temáticas de um contexto que ultrapassa um mero carácter situacional, emergindo deste modo a institucionalização da contestação num meio (re)conhecido de contestação de baixa intensidade, abafada na maior parte das vezes à nascença pelo comunitarismo exacerbado. Eis uma caraterização.

[...] droga tchiga Guiné i djumblintinu senariu/Nhu alferis ku nhu kabu/Tudu pasa sedu bida empresáriu [...] [A droga na Guiné baralhou-nos o cenário/Nho Alferes e Nho Cabo/Todos viraram empresários]Ai o ku Ntoni i chefi di alfandiga/I tene djaudi dja[Agora que o António é chefe da alfândega/Já tem dinheiro]I ka fasi nin 2 mis ki pudu la/Vida muda [Não faz nem dois meses que foi posto lá/E a sua vida mudou] Ali gos Ntoni tene kasa, tene karu, telemóvel/I ta troka mindjer suma ropa/I tene kumbu té na Eropa[Agora António tem casa, tem carro, telemóvel/Troca de mulher como quem troca de camisa/Tem dinheiro até na Europa]Si vensimentu i 5 mil/Si subsídiu i 2 mil/Nunde ki sai ku es manga di kusas?/ no ka sibi! [0 seu salário é 5 mil/O seu subsídio é 2 mil/ Onde é que arranjou essas coisas todas?/Não sabemos!] Amadu ki chefi di izersitu/Iooode/I ka fasi nin 2 dia ki tchiga la/Iooode/I mata Djokin i subi la[Amadu é chefe do exército/Iooode/Não há dois dias que chegou lá/Iooode/Matou Joaquim e subiu até lá]Ku asasinatu ku aumenta/korupson ganha forsa [Com o aumento dos assassinatos/A corrupção ganhou força]I ta troka mindjer suma ropa/I tene kumbu té na Eropa[Troca de mulher como se troca de roupa/Tem dinheiro até na Europa]Nunde ki sai ku es manga di kusas?/no ka sibi! [Onde é que arranjou aquilo tudo?/Não sabemos!]. (Torres Gémeos, culpadus, registo sonoro, Bissau, 2008) 
Porém, importa dizer que, essa transição do campo de protagonismo dos rappers guineenses ficou marcado por cinco fatores decisivos: 1) aparecimento de um rapper como voz e animador de uma campanha política protagonizado pela primeira vez na histórica recente da democracia guineense; 2) realização de festivais nacionais da música rap; 4) criação dos estúdios de gravação no país; 3) um sistema eficaz de distribuição informal das músicas; 5) eventos comemorativos dos aniversários da Rádio Jovem e dos agrupamentos e rappers mais populares.

Analisando o primeiro fator enumerado, convém esclarecer que não se trata da ordem de importância, mas apenas da cronologia dos acontecimentos, considera-se que o fenómeno Naka B., ao irromper para os palcos da campanha política nas primeiras eleições pós-conflito de 1998/99, protagonizou curiosidades e mobilizou os jovens para o debate político através das suas mensagens de intervenção com as músicas "coli-coli sença, bô pistanu nô terra / bô danu nô bandera" [com licença, emprestem-nos a nossa terra, entreguem-nos a nossa bandeira] e o "rigimi di crimi" [regime de crime], criticando o falhanço dos diferentes regimes que vigoraram no país e reclamando o direito a paz e ao desenvolvimento.

Também o facto de o Naka B. ter conseguido gravar num estúdio profissional (em África, Dakar), despertou os rappers guineenses a procurarem possibilidades de gravação na proximidade, visto que dantes a maioria pensava (sonhava) nas inacessíveis editoras na Europa, e ainda, proporcionou maior apreensão do movimento hip-hop no país vizinho (com tradição mais antiga).

A realização dos festivais da música rap "Guiné na Lanta” [Guiné Renasce] em 200015, “Outra face da droga”, em 2007, e “Esta Ter- 
ra é Nossa!", em $2010^{16}$, contribuíram para reforçar a condição do rap como uma expressão musical onde a palavra é democratizada pelos jovens com criatividade e atualização músico-cultural, e consequentemente inovar na produção do rap guineense. Este aspeto pedagógico dos festivais é estruturante.

Estes eventos ajudaram a consagrar grupos como Real Power e $\mathrm{MVD}^{+}$, além de temas como "crise na Guiné" - "Lus ka ten iagu ka ten [...] pon sta karu!/Lus ka ten iagu ka ten [...] arus sta karu!/Bô disa kurti karu! " [Não há luz não há água/O pão está caro!/Não há luz não há água/0 arroz está caro!/Párem de curtir carros!] (MVD ${ }^{+}$Crisi na Guiné, registo sonoro, Bissau, 2000).

Agora, para que haja música é preciso fazê-la. Este aspeto vai ser decisivo na manutenção, animação e atualização deste estilo com características identitárias nacionais. Se é verdade que começou-se a fazer a música rap no país de forma artesanal com as rádios, depois no estúdio Gumbé, mas sem capacidade de masterização e produção de beats originais, foi de facto na segunda metade do ano 2000 que surgiram estúdios de gravação profissionais e capazes de ir ao encontro das necessidades dos rappers, quer do ponto de vista qualitativo como quantitativo. De referir que existem neste momento no país cerca de oito (8) estúdios, algo que contribuiu para maior capacidade aquisitiva dos rappers no acesso aos beats.

Um outro aspeto importante na difusão dos temas produzidos é a questão da distribuição. Numa economia de baixa renda, fraca capacidade aquisitiva e que obedece a lógicas não convencionais ou informais, os transportes urbanos de Bissau TUB, vulgos "toca-toca", devem ser considerados como atores ativos deste processo. Sendo na maior parte os jovens que operam nesse circuito (condutores, cobradores, ajudantes, angariadores de clientes), ora sintonizavam em direto as emissões

${ }^{16}$ Os dois últimos organizados em 2010 pela GNT e Fórum Jovem de Bairro de Belém. 
do programa "Ondas Culturais", ora passavam os seus próprios repertórios que gravavam.

Isto permitiu que os "toca-tocas" conectassem áreas periféricas com o centro e, principalmente, o maior mercado do país, Bandim, levando a música rap juntamente com as pessoas durante os percursos. Entendemos que este elemento assume uma função chave na medida em que os meios de consumo coletivos vêm juntar-se aos meios de circulação (comunicação e transporte), e a concentração espacial dos meios de (re) produção, de troca e ainda das formações sociais, tornou indubitável o fervilhar dos seus efeitos e impactos na vida de uma cidade, sobretudo quando se trata da capital.

Por fim, e não menos importante, o fator concertos/espetáculos. Quando a Rádio Jovem anunciou pela primeira vez que iria comemorar o seu aniversário com atuações dos rappers autores das músicas que marcaram o top mensal do programa "Ondas Culturais", estava-se a preparar para consagrar o rap guineense como uma das dinâmicas cultural e política de maior impacto ao nível da capital da década de 2000-2010.

Os seus fazedores foram igualmente consagrados como os novos ídolos, não apenas da juventude, mas da sociedade bissauguineense na atualidade. Daqui para frente, foram várias iniciativas que os grupos e rappers realizaram para marcar a data da sua criação ou lançamento da primeira música, permitiu juntar em diferentes momentos e nos mesmos palcos os rappers que nunca tinham tido oportunidades para fazer um concerto, ou gravar um CD e, de um momento para outro, terem os concertos completamente esgotados, aproveitando a ocasião para lançamento e apresentações de novos temas.

Ao fazermos recurso ao Goffman (1973), deparamos com o palco (de espetáculo) enquanto elemento da interação entre atores sociais é apresentado como um desempenho, vivenciado de forma a causar uma impressão e, deste modo, influenciado pelo 
ambiente e audiência, que passa a desencadear novas formas e abordagens na representação e usos do rap guineense.

Ao nosso ver, são também baseados nesses pressupostos do desempenho e da impressão que poderá redefinir as identidades e as mensagens do rap guineense, hoje indubitavelmente mais de intervenção. Assim, temos o rap «revolucionário», e começando a emergir já no espaço de audiência e de confluência, sobretudo no seio dos jovens, para outras variações como são casos do rap «fashion» (ilustrado aspetos ligados a festas, divertimentos), o rap «romântico» (modalidade em que privilegia os temas de natureza amorosa e de carácter mais sentimental) e o rap «beef» (territorial e pessoal de apelo às rivalidades sobre o protagonismo a volta do culto do ego), este é mais visível no seio da comunidade rap guineense na diáspora ${ }^{17}$.

De uma forma geral, conseguiu-se superar os ditus (crítica dirigidas de forma indireta) pela lógica de enfrentamento para assumir abertamente e funcionalmente a responsabilidade e reiterabilidade da ação participativa e cidadã através de um meio que mais eficazmente podia trazer ao público a visão e reivindicação dos jovens sobre a sua condição e o seu futuro, nesse sentido, "No sidadi sta sukuru/pabia djintis buru/no ka ten futuru/ignorânsia ki no uru" [A nossa cidade está no escura/porque a gente é burra/não temos futuro/a ignorância é o nosso ouro]. (Parentis-D, no sidadi, registo sonoro, Bissau, 2000).

Assim, se na primeira fase da aparição do rap guineense, fazendo recurso a Chartterjee (2004), esta dimensão e impacto das

\footnotetext{
${ }^{17}$ Não obstante a essas variações existem ainda mais duas que, ao nosso ver, neste momento na Guiné-Bissau, pelas recolhas das músicas feitas junto às rádios, uma é de baixíssima intensidade (rap «gospel»), composto sobre temática intencionalmente religiosa e com função evangelizadora) e uma outra ausente, embora não implique necessariamente que não exista ou possa existir (rap «gangsta»). 0 mesmo que Radical: estilo de rap que se reporta às atividades ilícitas, violência e às atitudes machistas).
} 
rádios faz com que desempenhem o papel de palco, uma vez que adquirida a estrutura do convencimento, as músicas veiculadas conseguem ser suficientemente mobilizadoras de uma opinião pública, sobretudo na cidade capital não pelo aspeto lúdico, mas pela intervenção, ao passo que, no segundo momento, é no palco visível da atuação (concertos) que os rappers guineenses recuperam a sua presença em cena para consolidar o seu estatuto de tcholonaduris - "Bo obi mas ke ku ten ya/Bo obi, obi mas ke ku ten na Bissau" [Oiçam de novo o que se passa, ya/Oiçam, oiçam de novo o que se passa em Bissau]. (Baloberus, Bo obi mas, registo sonoro, Bissau, 2007).

\section{0 fenómeno "Masta T ito": 0 M C régulo ${ }^{18 ?}$ ?}

Enquanto manifesto cultural e político mobilizador, o rap guineense está a transformar a identidade sociocultural dos jovens, muito em particular nos centros urbanos, numa perspetiva de agentes mais dinâmicos dos processos reivindicativos e de protesto, em particular os rappers. Pela criatividade discursiva (lírico e musical) com efeitos narrativos e impactos reflexivos da representação (Martins, 2005; Pardue, em prelo) estes projetam um "eu/nós" transportando as suas experiências e as suas convicções, convertendo-se numa fórmula acessível de prática intensiva das identidades e estabelecendo assim, lógicas de autodefinição e automanutenção que garantam a subsistência ideológico-identitária sobre a relação que os indivíduos e grupos sociais estabelecem com os territórios (Martins, 2008, 35).

Indo à procura de um quadro teórico orientador dos protagonismos com altos níveis de visibilidade dos rappers guineense na última década, parte-se de três pressupostos: a) que as relações de negociação dos significados dos processos interativos e das relações sociais entre os sujeitos da situação social desencadeiam um

${ }^{18}$ Figura máxima do poder tradicional de algumas etnias. 
processo inevitável da visualidade (Martins e Barros, no prelo); $b$ ) que o rap constituiu-se num instrumento político de uma juventude excluída (Andrade, 1999), c) que o rap transformou-se num manifesto que penetra no quotidiano para descrever com poesia aquilo que é aparentemente desprovido dela (Jovino, 1999).

É deste modo que o rapper guineense Masta Tito ${ }^{19}$ integra a sua intervenção musical, concorrendo para aumentar a autoestima do protestar:

Si bu fala dur, nha pubis tene dur / si bu fala dur, guiniensis tene dur / dur di pulisias koruptus / di militaris ki so fuguia / di pulítikus muntrusis

[Se falares em dor, o meu povo tem dor / Se disseres dor, os guineenses sentem dor / Dor dos polícias corruptos / Dos militares que só sabem disparar / Dos políticos mentirosos] (Masta Tito, Dur di un Povo, registo sonoro, Bissau, 2011)

${ }^{19}$ Chama-se Tito Marcelino Morgado. Tem 28 anos, pai de uma filha e depois da passagem pelo movimento associativo juvenil, começou a cantar em 2002, com a música "Vampiro", na altura muito criticada por reportar palavras que muitos disseram serem "ultrajantes". Das suas mensagens retiram-se palavras duras e ostensivas ao poder político e militar, sobretudo. Atualmente trabalha para uma Organização Não Governamental Internacional no domínio da educação e saúde no Sul da Guiné. 


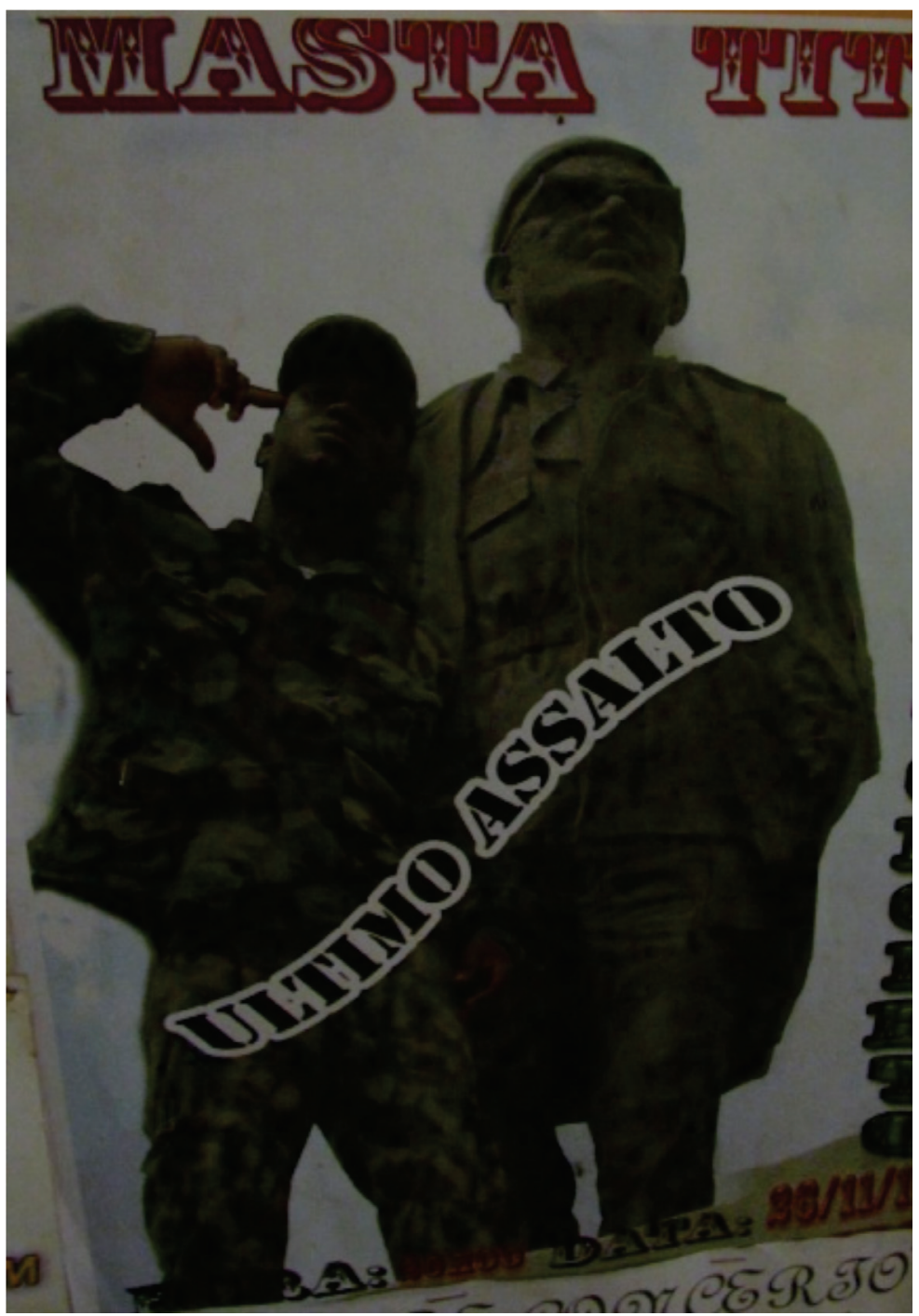

Imagem 1: Aspeto do cartaz do rapper Masta Tito junto estátua de Cabral, fundador da nacionalidade guineense. Fotografia de: Miguel de Barros 
A coragem do rapper em abordar de forma crítica, desde o primeiro momento, o bloqueio de um dos programas mais importantes da estabilização da Guiné-Bissau, a reforma de defesa e segurança, com palavras de ordem:

No misti reforma na forsas armadas / ba reforma i ka pirsis konfuson [Queremos a reforma das forças armadas / Para ir para a reforma não é preciso confusão] (Masta Tito, Governantins Katchuris, registo sonoro, Bissau, 2007)

Este, explora ainda as lutas políticas para controlo dos recursos do Estado numa perspetiva patrimonial, através de caricaturas corriqueiras que as representações de um simples cidadão comum consegue reconhecer e através dela manifestar-se. Vide por exemplo as passagens no tema "hora tchiga" no qual explora as divergências entre o partido do governo (Partido Africano para a Independência da Guiné e Cabo Verde - PAIGC) e o principal partido da oposição (Partido da Renovação Social - PRS):

Mandatu di Guiné-Bissau i tipo skola di nhu Baron / levantou sintou, sintou levantou/si i ka PRS i PAIGC si ka PAIGC i PRS / ora ku PAIGC na manda/PRS na sabotea/o PAIGC na sabótia se kabesa / ora ku PRS na manda/PAIGC na sabótia/ na pidi so Deus pel amor, pel amor di Deus / libranu di politikus muntrusis [0 mandato da Guiné-Bissau é tipo escola de Senhor Barrão / Levantou sentou, sentou levantou / Se não é o PRS é o PAIGC, se não é o PAIGC é o PRS / Quando for o PAIGC a governar / o PRS saboteia / ou o PAIGC saboteia-se a si próprio / quando for o PRS a governar / PAIGC saboteia / Só peço a Deus por amor por amor de Deus / Livra-nos dos políticos mentirosos] (Masta Tito feat Vladimir, Ora Tchiga, registo sonoro, Bissau, 2011)

E depois, denuncia o conflito entre o falecido Presidente da República, Malam Bacai Sanhá (MAMBAS) e o então Primeiro-Ministro, Carlos Gomes Jr., ambos pertencentes ao mesmo partido, e na altura do lançamento da música, ambos estavam no exercício, re-utilizando o slogan da campanha que levou a eleição do presidente: 
No na lestu di diskisi nunde ku no da tapada i nunde ku no kai / (...) Mambas falanuba kuma ora tchiga / gosi propi ku ora tchiga pa presidenti ku purmeru ministru kume na mesmu kabasa / (...) ora tchiga pa militaris para kume e farta e ba randja malkriadesa [Esquecemos depressa onde tropeçámos e onde é que caímos / (...) Mambas dizia-nos que chegou a hora / Agora é que chegou mesmo a hora de o presidente e o primeiro-ministro comerem no mesmo prato / (...) Chegou a hora de os militares comerem até se fartar e de cometerem desmandos] (Masta Tito, Ora Tchiga, registo sonoro, Bissau, 2011)

Na verdade, não foi apenas o estilo musical do rapper que contribuiu para a sua popularidade, mas sobretudo pelas perseguições que foi alvo por parte dos militares que controlam o poder político, chegando a ter concertos sucessivamente suspensos horas antes do seu início:

É músika na bai dedikadu pa tudu tropas maus... / Ke ku na medi jeneral? / tropas ka dudu pa matanu anós tudu / (...) es tropas ku sobritudu i falsu [Esta música é dedicada a todos os militares maus... / De quê tem medo o general? / Os militares não são doidos para matar-nos a todos / (...) estes militares que são sobretudo falsos] (Masta Tito, $\mathrm{Ke} \mathrm{Ku} \mathrm{Na}$ Medi, registo sonoro, Bissau, 2007)

\section{Aproveitando dessas situações, Masta Tito foi aumentando o seu repertório com mensagens de coragem e de produção de auto- estima, como se nota no tema "fosa":}

Si n medi, na muri / si n ka medi na muri / mindjor n ka medi, $n$ muri in diskansa / Masta Tito i régulu / régulu ka nunka medi / ami ki dunu di tchon / ami ku tene tera/ami ku ta manda na pulítikus, pulísias ku militaris... tudu djintis / kin ku iara nha dedu dentru di si kuku di udju / pa n kontal bardadi [Se tiver medo, morro / Se não tiver medo, morro / Melhor não ter medo, morrer e descansar / Masta Tito é régulo / Régulo nunca tem medo / Eu é que sou dono do chão / Eu é que tenho a terra / Eu é que mando nos políticos, nos polícias e nos militares... em toda a gente / A quem se comportar mal, enfio-lhe o dedo nos olhos / Para lhe dizer a verdade] (Masta Tito feat NB, Fosa, registo sonoro, Bissau, 2010) 


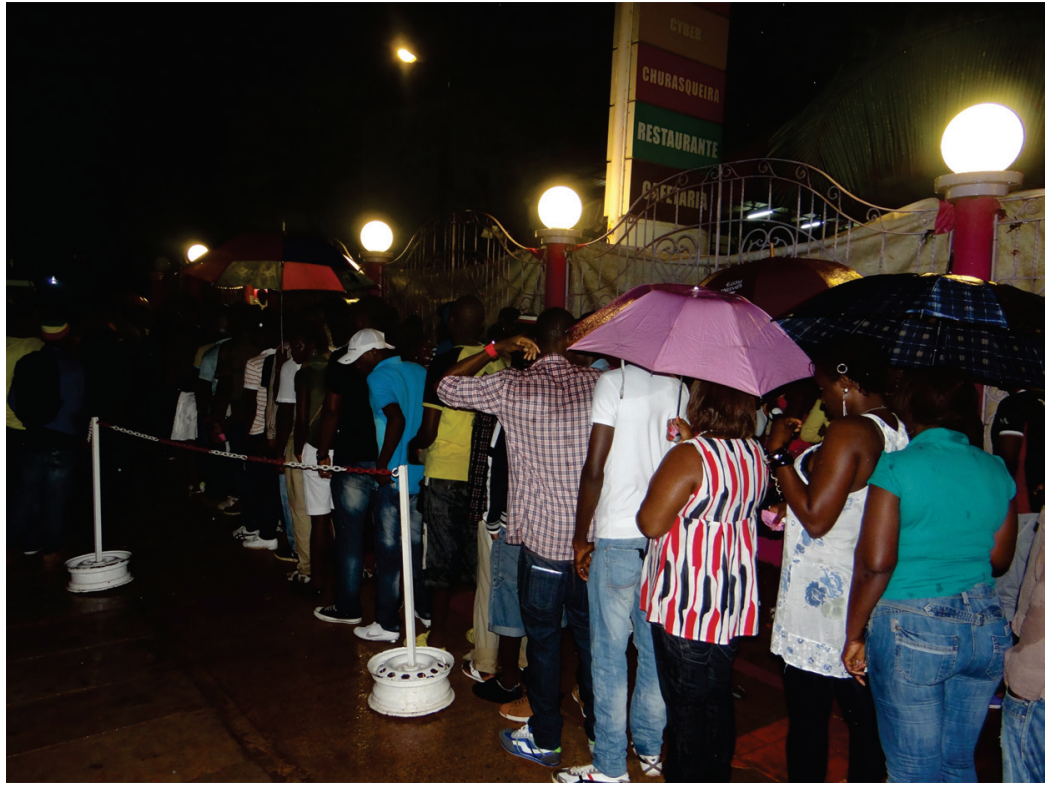

Imagem 2: Público em fila para acesso ao concerto do Masta Tito no espaço Lenox (Bissau, Setembro de 2012) Fotografia de: Miguel de Barros

Um outro elemento importante nas narrativas do Masta Tito é a sua aproximação e procura de cumplicidades junto ao público, como faz notar aqui nos temas "fidju botadu" e "n ‘ka na medi":

Ami i rasa kaseke/ $N^{\prime}$ ka ta medi iagu kinti/E na buskan pa pudi panhan/I pa kalantan/Ami n' disidi muri/Ma pa tudu mininus ten futuru! [Eu sou como o peixe seco/Não tenho medo da água quente/Andam à minha procura para me apanhar/E me fazer calar/Eu decidi morrer/Mas para que todas as crianças tenham futuro!] (Masta Tito, Fidju Botadu, registo sonoro, Bissau, 2007)

No ka na medi (...) / no karmusa no kansa / gosi i pa kada kin mara si kalsa / anós tudu i guiniensi / (...) bo gosta ó bo ka gosta $n$ ka na para kanta pa nha povu [Nós não temos medo / 
Cansámo-nos de nos pavonear / Agora que cada um amarre as calças / Somos todos guineenses / (...) Gostarem ou não gostarem, não vou parar de cantar para o meu povo] (Masta Tito, $N k a$ Na Medi, registo sonoro, Bissau, 2012)

Numa entrevista realizada à Rádio Voz da América $^{20}$, o rapper e intervencionista diz sentir-se "realizado, porquanto muitos consideram-no o porta-voz da maioria da população guineense" e afirma ainda que a sua popularidade advém do fato de expressar a verdade "só digo a verdade".

Com efeito, esta condição e auto-representação antes inquestionável, foi posta em causa no seio da comunidade rap guineense, em particular junto dos pares, na medida que o Masta Tito esteve implicado nas atividades da campanha eleitoral às eleições presidenciais de 2012, produzindo uma música apelando ao voto a este e participando nos comícios.

Anos i di Nhamadjo / (...) viva Nhamadjo / omi balenti / anós tudu no kontenti manera ku sta presenti / omi di paz / omi capaz/ Nhamadjo i AS / omi santu / (...) Nhamadjo ka susus / omi limpu pus / suma si pensamentu / pa Guiné mela tchut / (...) povo kudji paz / Nhamadjo bin ku paz / Nhamadjo i capaz/ povu misti paz /povu di Guiné no vota na Nhamadjo [Nós somos do Nhamadjo / (...) Viva Nhamadjo / Homem valente / Todos estamos contentes de ele estar presente / Homem de paz / Homem capaz / Nhamadjo é um ás / Homem santo / (...) Nhamadjo não é sujo / É limpo demais / Como o seu pensamento / Para que a Guiné seja só mel / (...) 0 povo escolheu a paz / Nhamadjo trouxe a paz / Nhamadjo é capaz / O povo quer paz / Povo da Guiné, votemos no Nhamadjo] (Masta Tito, Serifo Nheme Adjo, registo sonoro, Bissau, 2012)

Para muitos rappers, esta ação pôs em causa a condição de "régulo", na medida que contraria os princípios e valores deste mo-

\footnotetext{
${ }^{20}$ Ver em: http://www.voaportugues.com/portuguese/news/04_01_2011_guinerapper_ voanews
} 
vimento. Por outro lado, se dantes o rapper corria risco devido ao comportamento de militares que chegaram ao ponto de prender e torturar alguns rappers, Masta Tito passou a ter proteção dos militares, em particular do Chefe de Estado Maior General das Forças Armadas, algumas vezes, alvo das críticas do rapper, chegando este a ser convidado pela hierarquia militar a efetuar um espetáculo para elementos das forças armadas.

Estes fatos embora problemáticos, concorrem paradoxalmente para a popularização da personagem do rapper Masta Tito, fato confirmado, com a sua última música intitulada "no kansa golpe", em consequência do último golpe de Estado verificado no país:

Tudu ora son golpe/ pulitikus kusinha mas golpe / son golpe / militaris fasi mas golpe (No Kansa Golpe, 2012) [A toda a hora, só golpes (de Estado) / os políticos cozinharam mais um golpe / só golpes / os militares deram outra vez um golpe] (Masta Tito feat Ludy, No Kansa Golpe, registo sonoro, Bissau, 2012)

Neste registo, Masta Tito criticou diretamente políticos e militares com responsabilidades governativas, os principais candidatos às últimas eleições presidenciais (atendendo ao facto que o golpe de Estado ocorre quando se preparava para ir à segunda volta das eleições presidenciais) e parece quebrar o vínculo que o ligou ao então candidato presidencial e agora nomeado Presidente de República de Transição, afirmando:

Kulpasinhu kulpa garandi tudu i kulpa / golpesinhu ku golpe garandi tudu i golpe / kondena tudu i kondena / (...) Serifo Nhamadjo i presidenti pabia PRS fasi golpe [Culpa pequena, culpa grande, é tudo culpa / golpe pequeno e golpe grande, é tudo golpe / condenar é tudo condenar / (...) Serifo Nhamadjo é presidente porque o PRS deu um golpe] (Masta Tito feat Ludy, No Kansa Golpe, registo sonoro, Bissau, 2012) 


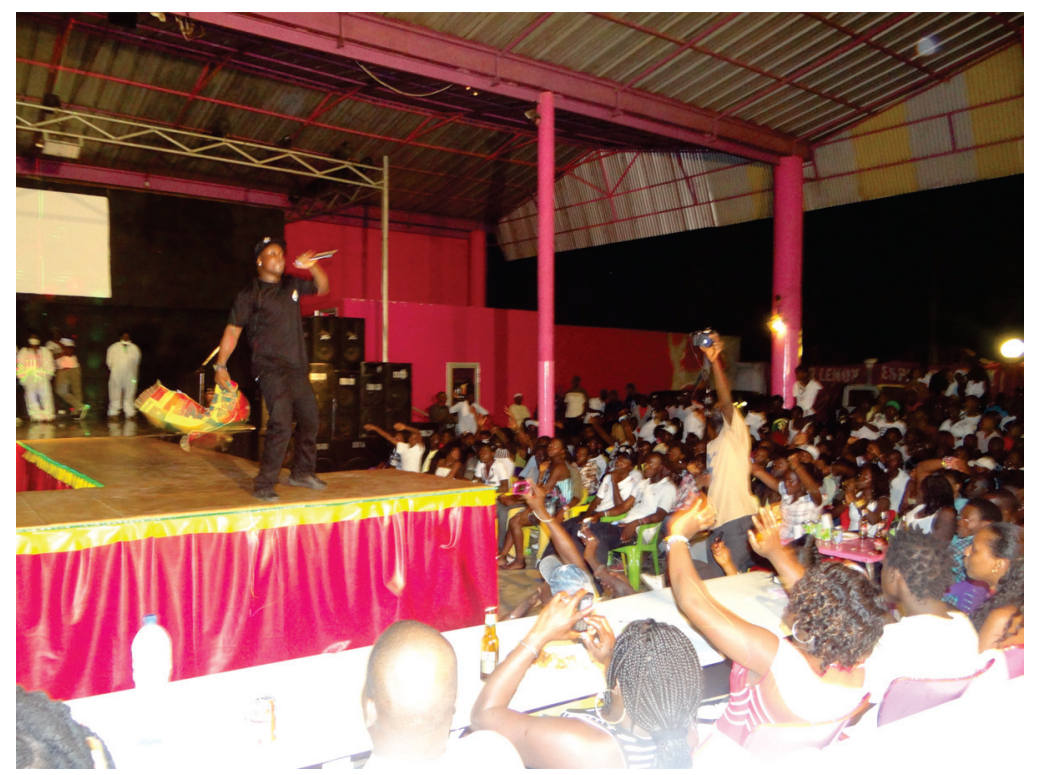

Imagem 3: Masta Tito em ação no espaço Lenox (Bissau, Setembro de 2012) Fotografia de: Miguel de Barros

Na verdade, segundo vários autores (Cardoso \& Augel, 1993; Koudawo \& Mendy, 1996; Barros, 2004; Teixeira, 2008) as eleições se tornaram, para a liderança política e militar, apenas mais uma estratégia de posicionamento dos interesses em detrimento dos interesses vitais das populações. É deste modo que os concertos dos rappers, antes e depois das eleições, em particular do Masta Tito caracterizam-se como algo que Azevedo \& Silva (1999) designam um espaço capaz de expressar e compartilhar sentimentos, comportamentos e valores culturais, possibilitando que tradições sejam evocadas e transformadas em novas linguagens. 


\section{Conclusão: democratizar a palavra e ampliar os espaços de participação a protagonistas não "tradicionais"}

Enquanto manifesto cultural e político mobilizador, o rap guineense transformou a identidade sociocultural dos jovens sem filiação partidária e/ou em estruturas formalizadas, marcadas pela mentalidade de "jitu ka ten" [não há solução], num projeto de contestação de reconhecimento através do seu protagonismo crítico-interventivo. Deste modo, devolveu o orgulho à juventude que é muitas das vezes criticada de não querer envolver-se na política ou de estar mais vulneráveis ao consumo.

Relativamente ao uso do crioulo, enquanto instrumento, e à rádio, como veículo de comunicação, potenciou a resistência e contestação dos rappers sobre a situação de instabilidade política e governativa, dos desmandos dos militares, da corrupção, do direito ao futuro, por um lado, e, por outro, desconstruiu para depois construir não só uma nova representação à música rap como também do protagonismo juvenil. Enfim, a palavra foi(é) desenvolvida e partilhada com o público nas múltiplas projeções e, como sustenta Queiroz (2007), a experiência rapper guineense extrapola os limites territoriais do país.

Um outro aspeto importante a convocar aqui é o recurso aos instrumentos, ritmos e sons tradicionais associados à recuperação dos temas clássicos dos grupos Cobiana Jazz e Super Mamadjombo, que contribuíram para ligar os jovens à história da resistência no seu país. Este processo consagrou a geração marcada pela guerra civil de 7 de Junho de 1998 e, por consequência, mobilizou-os para as lutas "libertadoras". Ao contrário de dinâmicas nos outros contextos, viram no rap uma forma sobretudo de ação cívica e de desafiar as desigualdades sociais existentes, focalizando-se na necessidade de construção do Estado, através da governação. Contudo, este facto prende-se com a particularidade do contexto histórico- 
-político que a Guiné-Bissau tem-se confrontado, desde a liberalização política até a atualidade.

De qualquer modo, se tomarmos como base que a construção de uma democracia participativa exige ações de mobilização, esta passa a ser fundamental para o exercício da cidadania. Num formato em que se torna imprescindível uma interlocução entre o Estado e a Sociedade Civil, a organização dos sujeitos em grupos não formalizados em torno dos temas de interesse público é a forma de ampliação da sua potência cívica, o meio através do qual podem intervir mais ativamente no debate público e chegar às instâncias deliberativas.

Todo este conjunto compõe, portanto, um amplo espectro mobilizador. E é visível que, muitas vezes, os próprios movimentos ou projetos mobilizadores competem entre si pela atenção dos cidadãos ${ }^{21}$. Mas se, por um lado, projetos de mobilização são muitas vezes realizados como iniciativa isolada, muitos procuram articular-se com outros que se referem à mesma causa social ou a causas conexas. Podemos identificar também que as lutas sociais adquirem uma característica de luta por visibilidade (Melucci, 2001). Não apenas porque os movimentos ou projetos de certa forma competem pela atenção - e consequentemente pela adesão - dos cidadãos, mas também porque necessitam posicionar-se em relação à causa que defendem e assim buscar a todo tempo legitimação institucional.

Aí podemos identificar o papel da mídia. Tornando públicas as suas causas e as suas ações, procuram com isso reforçar sua potência cívica, para colocarem-se como legítimos interlocutores ou mesmo para ganharem simpatia para a causa. Diante desse

${ }^{21}$ Recuperando Mbembe (1985), este aspeto torna-se extremamente crítico no caso dos rappers guineenses, na medida em que a situação de precariedade no qual vivem os jovens, sobretudo nas zonas urbanas (falta de oportunidades de formação, emprego, habitação), poderá levar a cooptação destes jovens, sobretudo pela dimensão na qual têm mais sucesso - a intervenção cívica. 
novo cenário, torna-se evidente que a questão da imagem assume posição central para os processos de mobilização. Este não é, no entanto, um processo simples, já que a pluralidade de interesses faz com que o espaço de publicização, através da mídia, tenha que ser todo o tempo reivindicado e conquistado.

Por isso mesmo, a mobilização constitui-se através de uma contínua formulação estratégica de ações de comunicação que sejam capazes de sustentar uma legitimidade pública (através da visibilidade), como também de sustentar os vínculos de confiança que mantêm a cooperação, que depende de uma capacidade de realimentar continuamente o debate público e reforçar os laços de identificação e de pertencimento dos sujeitos mobilizados. É nesta base que já se começam a notar um novo estilo no rap guineense, denominado por Contador e Ferreira de "filosofia de edutimento" [educação+divertimento], orientada para a sensibilização acerca de boas práticas e baseado no divertimento, introduzindo assim elementos dançáveis.

\section{Ref erências Bibliográficas}

Andrade, E. N. (1999). Hip Hop: Movimento negro juvenil. In E. N. Andrade (Ed.), Rap e educação: rap é educação (pp. 83-91). São Paulo: Summus;

Augel, M. (1998). A Nova Literatura da Guiné-Bissau. Bissau: INEP: Colecção Kebur;

Azevedo, A. M. G., \& Silva, S. S. J. (1999), “Os sons que vêm das ruas”, In Andrade, E. N. (Ed.), Rap e educação: rap é educação, São Paulo, Summus, p. 65-82;

BARROS, M. e LIMA, R. (em prelo). Rap Kriol(u):0 pan-africanismo de Cabral na música de intervenção juvenil na Guiné-Bissau e em Cabo-Verde. Realis - Revista de Estudos AntiUtilitaristas e PosColoniais;

Barros, M. (no prelo). 'Civil Society in the process of democratization and development in Guinea-Bissau (1991-2011)' In Olagboye, B. (ed.) Civil Society and Development in West Africa, WACSI;

Barros, M. (2010). Associativismo Juvenil Enquanto Estratégia de Integração Social: O caso da Guiné-Bissau. [Online] (URL http://repositorio-iul.iscte.pt/ 
bitstream/10071/2271/1/CIEA7_7_BARROS_Associativismo\%20juvenil\%20 enquanto\%20estrat $\%$ C3\%A9gia $\% 20 \mathrm{de} \% 20$ integra $\% \mathrm{C} 3 \% \mathrm{~A} 7 \% \mathrm{C} 3 \% \mathrm{~A} 3 \mathrm{o} \% 20$ social.pdf). (Accessed 20 november 2012);

Bennett, A. (2000). Popular Music and Youth Culture: Music, Indentity and Place, London: Macmillam;

Cardoso, C. \& Augel, J. (eds.) (1993), Guiné-Bissau 20 anos de independência: desenvolvimento e democracia. Balanços e perspectivas, Bissau, INEP;

Contador, A. \& Ferreira, E. (1997). Ritmo \& Poesia: Os Caminhos do Rap. Lisboa: Assírio \& Alvim;

Goffman, E. (1973). La mise en scène de la vie quotidienne. Tome 1: La présentation de soi. Paris: Minuit;

Goffman, E. (1973). La mise en scène de la vie quotidienne. Tome 2: Les relations en public. Paris: Minui

Henriques, M. et. al. (2004). Comunicação e estratégias de mobilização social. Belo Horizonte: Autêntica;

ICG (2012). "Au-dela des compromis: les perspectives de reforme en Guinée-Bissau", in Rapport Afrique n.183, Dakar/Bruxelles, 23 Janvier 2012;

ICG (2009). "Guinea-Bissau: Beyond the Rule of the Gun", in Policy Briefing, $n$. 61. Dakar/Bruxelas;

Jovino, I. S. (1999), "Rapensando PCN's”, In ANDRADE, E. N. (Ed.), Rap e educação: rap é educação, São Paulo, Summus, p. 161-168;

Koudawo, F. (2000). 'Os Media na Guiné-Bissau '. In Nick, S. (ed.) Pluralismos de Informação nos PALOP. Cascais: Principia/ Instituto PANOS, pp. 97-126;

Koudawo, F. \& Mendy, P. (eds.) (1996). Pluralismo Politico na Guiné-Bissau uma transição em curso, Bissau, INEP;

Martins, J. S. (2008). A fotografia e a vida cotidiana: ocultações e revelações. In: Pais, J. M., Carvalho, C. \& Gusmão, N. (Orgs.). $O$ Visual e o Quotidiano, Lisboa: ICS, 2008, pp. 33-58;

Martins, R. \& Barros, M. (no prelo). "Da in/visibilidade da representação e sentido de pertencimento nos coletivos periféricos de jovens em São Paulo e Lisboa";

Martins, R. (2005). Hip-Hop: O estilo que ninguém segura, São Paulo, Esetec;

Mbembe, A. (1985). Les jeunes et l'ordre politique en Afrique noire. Paris: L'Harmattan; 
PARTICIPAÇÃO POLITICA JUVENIL EM CONTEXTOS DE "SUSPENSÃO" DEMOCRÁTICA: A MÚSICA RAP NA GUINÉ-BISSAU

Melucci, A. (2001). A Invenção do Presente. Movimentos sociais nas sociedades complexas. Petrópolis: Vozes;

MEPIR, (2011). Documento de Estratégia Nacional de Redução da Pobreza/DENARP II. Bissau: MEPIR;

Parude, D. (no prelo). "Chronotope Identification in Kriolu Rap", In MARTINS, R. e CANEVACCI, M. (Orgs.), "Who we are" - "Where we are": identities, urban culture and languages of belongings in the Lusophone hip-hop, Oxford: Sean Kingston Publishing;

Queiroz, A. (2007). As Inscrituras do Verbo: dizibilidades performáticas da palavra poética africana, Tese apresentada ao Programa de Pós-Graduação em Letras da UFPE para a obtenção do título de Doutor em Teoria da Literatura: Recife: UFPE;

Sclavi, M. (2000). Arte di Ascoltare e Mondi Possibili. Milano: Le Vespe;

Schwarz, J. (1997). 'Ke ki mininu na tchora'. In Augel, M. (ed.) Ora di kanta tchiga: José Carlos Schwarz e o Cobiana Djazz. Bissau: Instituto Nacional de Estudos e Pesquisa (INEP), p.49. (Colecção Kebur);

Semedo, O. (2010). Guiné-Bissau: história, culturas, sociedade e literatura. Belo Horizonte: Nadyala;

Silva, L., and Kayayan, A. (eds), (2004). Estratégias de Comunicação e Mobilização Socia, Brasília: Universa;

Teixeira, R. (2008). A Construção Democrática na Guiné-Bissau: Limites e Possibilidades, Conferência sobre Pluralismo Político e Democracia na Guiné-Bissau, Bissau 17-18 Outubro, CODESRIA;

UNODC (2008). Perspectives, Issue 5, Viena, May 2008;

UNODC (2007). Cocaine trafficking in West Africa: the threat to stability and development (with special reference to Guinea-Bissau), Viena, December;

Zumthor, P. (1987). La letra y la voz, Madrid: Cátedra.

Recebido em 01/10/2012

Aprovado em 15/11/2012 